\title{
Enhancing communication and participation using AAC technologies for children with motor impairments: a systematic review'
}

\author{
Nicole Bianquin*, Fabio Sacchi*, Serenella Besio**2
}

\begin{abstract}
The present systematic review investigates studies carried out in the period 2007-2017, focusing on the use of technologies for augmentative and alternative communication (AAC) with the aim of improving the communication processes of persons (0-18 years) with complex communication needs related to motor impairments. Specifically, work develops an analysis of both the technological devices proposed and their effects on the implementation of the communication processes. The included studies are characterized by the heterogeneity of the proposals. The solutions presented and their evaluations return a complex framework in which multiple variables can influence the effectiveness and the success of the technological experiences. Finally, the study attempts to identify the future and possible areas that still need to be investigated and explored in the field of the AAC technologies. However, from the analysis of the included papers, it emerges that improvements in the research designs, in the evaluation tools and in the presentation of the results it is strongly necessary to ensure greater understanding of the results obtained.
\end{abstract}

Keywords: disability, augmentative and alternative communication (AAC), inclusion process, technologies.

\footnotetext{
${ }^{1}$ The article has been designed by all authors. Nicole Bianquin wrote the Introduction and paragraphs 3 (ST1, ST2, ST3, ST4), Fabio Sacchi wrote paragraphs1, 2 and 3 (ST5, ST6, ST7), Serenella Besio wrote the paragraph 4 and all authors wrote the Conclusion.

$2 *$ University of Aosta Valley, Department of Human and Social Sciences, ** University of Bergamo, Department of Social and Human Sciences. Nicole Bianquin is a pedagogist and support teacher in primary school. She accomplished her Ph.D. studies in "Quality of education: development of knowledge and differences" at the Università degli Studi di Firenze (I) in 2012. She is currently Fellow Researcher at the Department of Human and Social Sciences of the Università della Valle d'Aosta (I). She's currently Adjunct Professor of Special Didactics and Teaching Assistant for the course of Special Education at the Università della Valle d'Aosta (I). Her main research interests concern the inclusive processes within the school system, and in particular the methods of evaluation and self evaluation of the school inclusion quality, and the inclusive education and didactics.
} 


\section{Introduction}

In order to fully develop all human rights and fundamental freedoms granted to all person and in order to further equalize opportunities specifically for persons with disabilities, it is essential to recognize, as stated in the UN Convention on the Rights of Persons with Disabilities (UN, 2006), a political and operational principles and guidelines. A founding core within these principles is represented by communication, recognized by the Convention (Article 2) as one of the most effective and appropriate ways to promote and implement a process of scholastic progress and social development for persons with disabilities in order to ensure the maximum of participation. The possession of adequate interpersonal communication skills is therefore a fundamental prerequisite for well-being of every student, for development and for an effective social inclusion. The Convention conceives the communication as a complex and articulated set consisting of languages, text visualizations, Braille, tactile communication, accessible multimedia sources as well as written, audio, alternative and augmentative communication methods, means and formats, including accessible communication and information technologies.

The ability to communicate is essential for human beings. Communication enables to express needs and desirers, to socialize with others, to convey information, and to participate in society. About $1.3 \%$ of people have serious communication difficulties, can not use oral language to express their daily needs (Beukelman \& Mirenda, 2005) and has difficulty making themselves understood (Lindsay, Dockrell, Desforges, Law, \& Peacey, 2010). These people, unable to speak, encounter considerable limitations in communication and in participation in all their life aspects - education, medical care, work, family, social participation - if they are not given other means of communication. The International Classification of Functioning, Disability and Health (WHO, 2001) frames the area of communication, as one of the nine domains founding the life of a person (Activities and Participation), defining it as general and specific features, language, signs and symbols, including the production (identified with the codes: d330 - speaking; d335 - producing nonverbal messages; d345 - writing messages) and reception (d310 - receiving spoken messages; d315 receiving nonverbal messages; $\mathrm{d} 325$ - receiving written messages) of messages, carrying on conversations (d350), discussion (d355) and the use of devices and communication techniques (d360). When the ICF addresses the topic of communication, it explicitly indicates the possibility of communicating, both in the receptive and productive phase, with non-verbal messages, meaning messages conveyed by gestures, symbols (such as icons, bliss board, scientific symbols) and drawings. 
The impossibility of developing any communication system, alternative to the verbal one, could imply many limitations for individual growth and wellbeing, such as for example a reduction of the learning possibilities in the school as well as in all daily situations, where it is possible to acquire information and skills. Similarly social integration could remain compromised in all the areas of daily life: school, leisure, work. And finally the emotional well-being of the subject may be damaged: when appropriate tools to communicate (emotions, needs, desires, preferences, ...) are not present, in many cases the only solution often remains specific behaviors, very often identified as problematic, as a means of attracting the attention of others and for communicate the discomfort. The development of alternative forms of communication, not exclusively support for spoken language, in these cases, generally could decrease inappropriate behaviors, with a consequent improvement in individual well-being. It then becomes essential to strengthen the existing communication methods, supporting them with tools that allow to overcome the communication deficit and to reactivate relations with the outside world.

For persons with complex communication needs, with motor and speech impairment, the programs that include the use of the Augmentative and Alternative Communication (AAC), represent an interesting help in offering a bridge to others and to the world (Beukelman \& Mirenda, 2005). The Alternative Augmentative Communication has the purpose of increasing communication involving a wide range of techniques, strategies, and technologies to support and augment the communication of the individual with complex communication needs (Cook \& Polgar, 2012) and is designed to support and foster the abilities, preferences, and priorities, taking into account motor, sensory, cognitive, psychological, linguistic and behavioral skills, strengths and challenges of the person.

The AAC is a multidisciplinary area in which many professionals, speech therapists, occupational therapists, physiotherapists, psychologists, educators, linguists, engineers, programmers and many others intervene, making specific contributions. To learn and use AAC effectively as part of everyday life is not a task done occasionally and does not appear in isolation. Every person using AAC needs a network of people around them, some with a preparation and a formal remit to work on communication and others who have exchanges of communication on an informal level more personal, social, work, related or educational some level. All these people, however, have a role in helping the AAC system to function effectively and to help the user learn to communicate efficiently with AAC (Blackstone, Williams, \& Wilklins, 2007).

On the communicative side, persons with communication problems can be classified into three groups according to their needs (von Tetzchner \& Martinsen, 1992): 
- individuals who require expressive language that are unable to express themselves and they need a way to use their, often limited, motor skills to express and to communicate;

- individuals who need supportive language: people who can potentially speak, but the process of speech development have a delay or sometimes is unintelligible;

- individuals who are unable to communicate in any form of speech and require alternative language. They are unable to express themselves, and sometimes also to understand the speech of others.

- The AAC includes three interlinking strands (Royal College of Speech and Language Therapists, 2006):

- the communication medium, that is the meaning by which the message is transmitted. This can be unaided, for instance by using gestures, facial expression, signing, etc., or it can be aided (the person communicates using some sort of device other than their body, for instance via a communication chart, or an electronic device with speech output);

- the means of the communication medium access, such as for example a keyboard or a touch screen, or a switch to scan from an array of letter, words, or pictures on a monitor;

- the system of representing meaning, language or set of symbols. These symbols may be traditional orthography (letters or words), or they may be a set of pictorial symbols.

In order to meet all of the different needs of persons with complex communication difficulties, multiple communication methods and devices were developed. AAC systems are different: unaided communication uses no equipment and is 'no-technology', including body-centered methods such as speech, gestures, facial expressions and vocalizations. Gestural codes and formal manual sign systems are examples of more formal approaches. While aided approaches use external tools, both 'low-technology' (meaning inexpensive devices that are simple to make and easy to obtain, such as paper communication boards, cards and books) and 'high-technology' systems. The latter refers to devices that have electronic components including pointer boards, switches connected to devices, control device. Currently high technology for AAC is characterized by computer-based systems with text to speech software and sophisticate access methods like eye-gazing. High tech communication aids vary also in the level at which they require the user more or less sophisticated techniques of visual perception, memory, sequencing skills, language processing, meaning associations, grammar or encoding.

Most AAC users employ a number of different forms of communication systems, a mixture of unaided, aided, low and high tech aids, depending on 
the situation (Millar \& Scott, 1998); an estimated $0.05 \%$ of children and young people require high technology AAC (Gross, 2010).

The aim of this paper is to provide a comprehensive review of the most recent studies and researches that have developed and experimented AAC high technologies in order to support the communication process of children and adolescents with disabilities. The specific research questions are:

1. what are the most recent AAC technologies used to support the communication process of persons with motor impairments?

2. what are the features of the most recent AAC technologies used to support the communication process of people with motor impairments?

3. how effective these technologies are with respect to the communication process of persons with motor impairments?

\section{Systematic Review Method}

In order to select the studies to be included in the systematic review, a multi-phase procedure based on established guidelines (Kitchenham, 2004; Cochrane Library, 2011) was followed. After thorough discussions between the researchers about the goals of the systematic review and the inclusion and exclusion criteria, aimed at building a shared understanding and a common framework for the selection phases, the following steps were taken.

1. The databases were queried using the chosen keywords and bibliographic data and abstract for each identified document were registered.

2. Results from all database queries were merged and duplicates were removed.

3. Two independent raters examined the titles and abstracts of each retrieved study and applied the inclusion and exclusion criteria, taking note of their decisions of including or not the study. The two raters then compared their decisions and settled all differences through discussion. In cases where it was not clear from the abstract if the study should be included or not, the full paper was retrieved and analyzed to better support the decision.

4. Full-texts corresponding to all of the potentially relevant abstracts were obtained.

5. Full-text reports were examined for compliance of studies with eligibility criteria and final decisions on study inclusion were taken.

6. Selected papers were split between two of the researchers for data collection.

7. After each researcher having extracted the relevant information to a reading form, the other researcher went through the paper and the reading form for validation. Divergences were resolved by consensus. 
All studies reviewed in this article were identified by searching the following 17 electronic databases: Scopus, CINAHL, PubMed, Embase-Ovid, ERIC, PsycINFO, Web of Science, Psychology and Behavioral Sciences Collection, Inspec, Cochrane Library, Pedro, OTseeker, Education source, Access engineering, Computer Science 2016, OECD Science Technology and Industry Scoreboard, IEEE Xplore Digital Libray, RESNA conference proceedings. The search took place from 1 March 2018 to 2 March 2018.

Databases were queried using the following keywords (AND and OR represent the corresponding logical operators):

a) children, adolescents, youth, child, teenager;

b) physical disability, physically disabled, mobility impairment;

c) augmentative and alternative communication;

d) technology.

To systematize data collection, a reading form was created based on the model of Letts et al. (2007) including the following data items.

a) Bibliometric indicators of the publication: journal's name and SourceNormalized Impact per Paper (SNIP), when available, or conference proceedings title; year of publication; authors' names and countries of affiliation; DOI name; type of publication.

b) Characteristics of the study: type of study (review, intervention study, descriptive study); research design and methods using Letts et al. (2007) classification for qualitative research and Law et al. (1998) classification for quantitative research; sample information (sampling method, number of participants, age, gender, diagnosis); purposes; outcomes observed.

c) Characteristics of the technologies proposed in the selected paper: name; description; users; evaluation procedure; effects on the communication process; adults' role.

\section{Main Results}

The databases searches identified 43 documents. After removing duplicates, 31 studies remained. Upon assessment of abstracts and full-texts, 7 studies were included in the systematic review (Table 1) according to the inclusion and exclusion criteria defined. The inter-rater reliability score was $87.1 \%$ (good) and a Cohen's kappa coefficient (Cohen, 1960) of 0.68 (good) was obtained. 
Table 1 - Selected articles

\begin{tabular}{|l|c|l|c|}
\hline Title of the paper & $\begin{array}{c}\text { Year of } \\
\text { publication }\end{array}$ & \multicolumn{1}{|c|}{ Authors list } & I.D. \\
\hline $\begin{array}{l}\text { An augmentative and alternative communication } \\
\text { tool for children and adolescents with cerebral } \\
\text { palsy }\end{array}$ & 2015 & $\begin{array}{l}\text { CE Saturno, ARG Ramirez, } \\
\text { MJ Conte, JF da Silva, M } \\
\text { Farhat, FdM G. Garcez, AC } \\
\text { Savall, EC Piucco }\end{array}$ & ST1 \\
\hline $\begin{array}{l}\text { Communicative interaction between a non- } \\
\text { speaking child with cerebral palsy and her } \\
\text { mother using an iPadTM }\end{array}$ & 2014 & M Pinto, H Gardner & ST2 \\
\hline $\begin{array}{l}\text { Design of an Iconic Communication Aid for } \\
\text { Individuals in India with Speech and Motion } \\
\text { Impairments }\end{array}$ & 2009 & S Bhattacharya, A Basu & ST3 \\
\hline $\begin{array}{l}\text { Digital games and assistive technology: } \\
\text { improvement of communication of children } \\
\text { with cerebral palsy }\end{array}$ & 2013 & $\begin{array}{l}\text { MIJ Ferreira, XL Travassos, } \\
\text { R Sampaio; CdS Pereira- } \\
\text { Guizzo, L Alves }\end{array}$ & ST4 \\
\hline $\begin{array}{l}\text { Eye gaze technology: A South African } \\
\text { perspective }\end{array}$ & 2014 & K van Niekerk, K Tönsing. & ST5 \\
\hline $\begin{array}{l}\text { Happy and excited perception of using digital } \\
\text { technology and social media by young people } \\
\text { who } \\
\text { use augmentative and alternative } \\
\text { communication }\end{array}$ & 2014 & $\begin{array}{l}\text { A Hynan, JM Juliet, J } \\
\text { Goldbart }\end{array}$ & ST6 \\
\hline $\begin{array}{l}\text { The experience of speech recognition software } \\
\text { abandonment by adolescents with physical } \\
\text { disabilities }\end{array}$ & 2014 & $\begin{array}{l}\text { R Van Schyndel, A Bhargava } \\
\text { Furgoch, T Previl, R Martini }\end{array}$ & ST7 \\
\hline
\end{tabular}

\section{Bibliometric indicators}

All the selected studies were published in scientific journals in the last five years, only one of them (ST3) before the year 2013. The normalized impact factor ${ }^{3}$ of these journals was low: average SNIP ${ }^{4}$ of 1.13 (SD 0.49) and, according to the SJR journal classification ${ }^{5}$, were located mostly at the Q2 journal quartile ${ }^{6}$. The

${ }^{3}$ Tool for assessing the scientific quality of journals in different disciplines (Owlia et al., 2011).

${ }^{4}$ SNIP is the ratio of the journal's citation count per paper and the citation potential in its subject field (Moed, 209).

${ }^{5}$ Measure of the prestige of the magazines present in Scopus database.

${ }^{6}$ Quartile rankings are: Q1 denotes the top position, Q2 for middle-high position (between top $50 \%$ and top 25\%), Q3 middle-low position (top $75 \%$ to top 50\%), and Q4 the lowest position (bottom $25 \%$ of the IF distribution). The rankings derive from the impact factor. 
Hirsch Index (HI) ${ }^{7}$ was 28.1 (SD 13.08). The studies were conducted in Canada (1), in the U.K. (2), in Brazil (2), in South Africa (1), in India (1). Four papers were journal articles and three were research articles. All the selected studies were published in peer reviewed scientific journals.

\section{Characteristics of the studies}

Only four studies provided information about the selection of the participants: in two cases are volunteers (ST1, ST3) and in the other two cases the sample is non probably (ST4, ST6). A total number of 41 children from the age of 8 to 18 years old were involved. Three studies deal only with children (ST3, ST4, ST6), others involved children and parents (ST1 ST2, ST7), and only a study provides for the presence of children, parents and caregivers, understood as therapists and teachers (ST5). Only four of the seven studies provided information on the participants' gender: nine females and five males. Most of the studies are aimed at individuals diagnosed with cerebral palsy (CP); the other diagnoses are attributable to motor impairments as shown below (Table 2).

Table 2 - Study participants

\begin{tabular}{|l|l|l|l|l|l|}
\hline Study & Diagnosis & $\begin{array}{l}\text { Participants } \\
\text { with disability }\end{array}$ & $\begin{array}{l}\text { Participants } \\
\text { with typical } \\
\text { development }\end{array}$ & Parents & $\begin{array}{l}\text { Caregivers } \\
\text { (speech } \\
\text { therapist } \\
\text { or teachers) }\end{array}$ \\
\hline ST1 & Choreoathetosis & Not specified & Not included & Included & Included \\
\hline ST2 & $\begin{array}{l}\text { Quadriplegic } \\
\text { athetoid cerebral } \\
\text { palsy and seizure } \\
\text { disorder }\end{array}$ & 1 & Not included & Included & Not included \\
\hline ST3 & $\begin{array}{l}\text { Athetoid cerebral } \\
\text { palsy Spastic } \\
\text { cerebral palsy } \\
\text { Friedrich's ataxia } \\
\text { Multiple sclerosis }\end{array}$ & 4 & Not included & Not included & Not included \\
\hline ST4 & $\begin{array}{l}\text { Cerebral palsy, } \\
\text { nonspeaking, light } \\
\text { hearing impairment } \\
\text { and light motor } \\
\text { impairment. }\end{array}$ & 3 & Not included & Not included & Not included \\
\hline
\end{tabular}

${ }^{7}$ Hirsch Index is a criterion for quantifying the prolificacy and scientific impact of an author, based both on the number of publications and on the number of citations received. 
Table 2 - continued

\begin{tabular}{|l|l|l|l|l|l|}
\hline Study & Diagnosis & $\begin{array}{l}\text { Participants } \\
\text { with disability }\end{array}$ & $\begin{array}{l}\text { Participants } \\
\text { with typical } \\
\text { development }\end{array}$ & Parents & $\begin{array}{l}\text { Caregivers } \\
\text { (speech } \\
\text { therapist } \\
\text { or teachers) }\end{array}$ \\
\hline ST5 & $\begin{array}{l}\text { Dystonic cerebral } \\
\text { palsy and severe } \\
\text { bilateral hearing loss }\end{array}$ & 2 & Not included & Included & Included \\
\hline ST6 & $\begin{array}{l}\text { Level V of Gross } \\
\text { Motor Function } \\
\text { Classification } \\
\text { System }\end{array}$ & 25 & Not included & Not included & Not included \\
\hline ST7 & $\begin{array}{l}\text { Physical disability } \\
\text { affecting hand } \\
\text { writing performance } \\
\text { and efficiency }\end{array}$ & 3 & Not included & Included & Not included \\
\hline
\end{tabular}

Within the seven studies three were quantitative (ST3, ST4, ST5), three were qualitative (ST2, ST6, ST7) and one was both qualitative and quantitative (ST1) (Table 3). Most qualitative studies used a phenomenological design type and only one used grounded theory. All quantitative studies used cohort design (without control group) except one that used case study.

The quality level of the research drawings of the studies was evaluated later on the basis of the Centre for Reviews and Dissemination Hierarchy of Evidence (2007): a 5-scale ${ }^{9}$ in descending order which considers to a high degree (level 1) the evidence resulting from experimental studies and low evidence (level 5) those from observational studies and without control groups. The researches included in the present work were located on the third and fourth levels of this scale (cohort studies, case studies and observational studies).

${ }^{8}$ Children are transported in a manual wheelchair in all settings. Children are limited in their ability to maintain antigravity head and trunk postures and control leg and arm movements.

${ }^{9}$ The levels are: experimental studies (I), quasi-experimental studies (II), controlled observational studies (III), cohort studies (IIIa), case control studies (IIIb), observational studies without control groups (IV), expert opinion based on theory, laboratory research or consensus (V). 
Table 3 - Study types

\begin{tabular}{|l|l|l|l|l|}
\hline I.D. & Study design & Design type & Methods & Data collection process \\
\hline ST1 & Quantitative & $\begin{array}{l}\text { Cohort design without } \\
\text { control group }\end{array}$ & $\begin{array}{l}\text { Questionnaire } \\
\text {-Interviews }\end{array}$ & Statistical analysis \\
\cline { 2 - 5 } & Qualitative & Phenomenological & $\begin{array}{l}\text { Interviews - } \\
\text { Video recording }\end{array}$ & Not specified \\
\hline ST2 & Qualitative & Phenomenological & $\begin{array}{l}\text { Audio recording of } \\
\text { the spontaneous } \\
\text { interactions }\end{array}$ & Conversation analysis (CA) \\
\hline ST3 & Quantitative & $\begin{array}{l}\text { Cohort design } \\
\text { without control group }\end{array}$ & $\begin{array}{l}\text { Recording of speed } \\
\text { of communication }\end{array}$ & Statistical analysis \\
\hline ST4 & Quantitative & $\begin{array}{l}\text { Cohort design } \\
\text { without control group }\end{array}$ & $\begin{array}{l}\text { Recording of, } \\
\text { frequency and } \\
\text { accuracy }\end{array}$ & Statistical analysis \\
\hline ST5 & Quantitative & Case study & Interviews & Not specified \\
\hline ST6 & Qualitative & Grounded theory & $\begin{array}{l}\text { Semi-structured } \\
\text { interviews }\end{array}$ & $\begin{array}{l}\text { Software analysis of } \\
\text { narrative data }\end{array}$ \\
\hline ST7 & Qualitative & Phenomenological & $\begin{array}{l}\text { Narrative inquiry - } \\
\text { Audio recording - } \\
\text { interviews }\end{array}$ & $\begin{array}{l}\text { Transcription, analysis } \\
\text { using plot-solution }\end{array}$ \\
\hline
\end{tabular}

The studies had several aims: describing and presenting technological solutions for the AAC (ST1, ST3), investigating and analyzing the effects of technology on the communication process (ST2, ST4, ST5), describing the user experience in the relationship between AAC and social media (ST6) and understanding the motivations and variables that influence the experiences of technologies' abandonment (ST7).

The outcomes highlighted both positive and critical elements in relation to the use of technologies for the AAC. Four studies presented positive results showing how the technologies can support the participation process and social inclusion (ST1, ST3, ST4, ST6). Instead, a study reported negative results (ST2), highlighting how in the case of severe motor impairments the development of communicative autonomy remained limited.

ST5 highlighted how the use of AAC technologies could be strongly correlated to an ecological perspective in which the risk and benefit factors are influenced by multiple variables related to different aspects and contexts. The latest study (ST7) also stated the importance of a deeper knowledge of the different factors related to the communication process. 
Table 4 - Study purposes and outcomes

\begin{tabular}{|c|c|c|}
\hline Study & Study Purposes & Study Outcomes \\
\hline ST1 & $\begin{array}{l}\text { To describe two solutions developed one } \\
\text { for desktop computers and one for mobile } \\
\text { devices }\end{array}$ & $\begin{array}{l}\text { The solutions presented act as complements } \\
\text { of therapist's activities, helping persons with } \\
\text { disability to communicate, and promoting } \\
\text { social inclusion }\end{array}$ \\
\hline ST2 & $\begin{array}{l}\text { To establish how a tablet form of AAC is } \\
\text { exploited in day-to-day domestic interactions } \\
\text { between a parent and a child }\end{array}$ & $\begin{array}{l}\text { The child typically remains a respondent } \\
\text { to initiations by the caregiver, who in this } \\
\text { scenario necessarily remains in control of } \\
\text { the iPad symbol display }\end{array}$ \\
\hline ST3 & $\begin{array}{l}\text { To present an icon-based communication aid } \\
\text { software }\end{array}$ & $\begin{array}{l}\text { The proposed software is able to provide an } \\
\text { interface that is intuitive and user-friendly, } \\
\text { qualities that are very important to increase } \\
\text { the acceptability of the system }\end{array}$ \\
\hline ST4 & $\begin{array}{l}\text { To analyze the frequency of occurrence } \\
\text { of different forms of communication in } \\
\text { nonspeaking children during activities with } \\
\text { digital games }\end{array}$ & $\begin{array}{l}\text { The digital games favored nonspeaking } \\
\text { children with Cerebral Palsy with the use } \\
\text { of different forms of communication. This } \\
\text { shows the importance of the attention } \\
\text { professionals should pay to every gesture } \\
\text { expressed by nonspeaking children also to } \\
\text { promote their interaction with people }\end{array}$ \\
\hline ST5 & $\begin{array}{l}\text { To provide a perspective on factors that } \\
\text { need to be taken into account in order to } \\
\text { facilitate communication and participation in } \\
\text { preliterate children making use of electronic } \\
\text { AAC systems accessed through eye gaze. }\end{array}$ & $\begin{array}{l}\text { The immediate environment as well as } \\
\text { meso, exo- and macro systemic issues (such } \\
\text { as societal attitudes and funding sources) } \\
\text { have a significant influence on benefits } \\
\text { derived }\end{array}$ \\
\hline ST6 & $\begin{array}{l}\text { To investigate the self-reported experiences } \\
\text { of the accessibility of the Intemet and online } \\
\text { social media by people who use AAC }\end{array}$ & $\begin{array}{l}\text { Participants have a desire to use the internet } \\
\text { and online social media as it is perceived to } \\
\text { increase opportunities for self-determination } \\
\text { and self-representation whilst enriching } \\
\text { friendships }\end{array}$ \\
\hline ST7 & $\begin{array}{l}\text { To describe the experience of adolescents } \\
\text { and their parents, who experienced } \\
\text { abandonment of SRS (speech recognition } \\
\text { software) }\end{array}$ & $\begin{array}{l}\text { Participants believed the SRS was not an } \\
\text { adequate fit for their needs or their specific } \\
\text { disabilities and so resorted to alternative } \\
\text { methods of written communication. A } \\
\text { better understanding of the compatibility of } \\
\text { the client's needs with the strengths and } \\
\text { limitations of the technology, may improve } \\
\text { the prescription and intervention process for } \\
\text { both therapists and their clients }\end{array}$ \\
\hline
\end{tabular}




\section{Characteristics of the technologies}

The technologies described in each research were investigated using the following categories and were used for subsequent comparisons: a short description of both the characteristics of the technologies and their operation, the information related to the users' needs, the types of communication, the adult's role and the evaluation process. Some of these categories had been identified starting from those used by Cook and Polgar (2012) to classify the technologies.

\section{\begin{tabular}{l|l} 
ST1 & AAC TOOL DESKTOP SOLUTION \& AAC MOBILE SOLUTION
\end{tabular}}

\section{AAC tool desktop solution}

Description: AAC tool desktop is a software based on communication cards and iconographic symbols allowing the user to select the desired symbols. Subsequently, the symbols are vocalized and added to the upper left side of the software interface. The software facilitates the choice of the first and subsequently symbols: symbols commonly used first are people and greetings then others are suggested according to the previous selected. The tool also provides sentences based on graph theory.

User communication needs: alternative language.

Type of communication: communication producing nonverbal message (d335) and conversation (d350).

Communication medium: aided communication using electronic device with speech output.

Input features and selection techniques: scanning using stapler device (emulates the click and double clicks functions of the mouse), adaptive devices (pressure switches) or adaptive stapler.

Messages characteristics (form of AAC and vocabulary expansion): pictures and text.

Output features: pictures oral description.

Accessory features: not indicated.

Adults' role: not indicated.

In this study the efficiency of the AAC tool desktop was evaluated through a dialogue prepared by the speech therapist. In a first stage the dialogue was initiated using the low technologies available at the center (communication boards) then the same dialogue was performed by using the software. Students involved in the study attempted an average rate of 15 symbols selections per 
minute when using low-tech communication boards. When using the system, those rates were worse, sometimes no coherent phrases were constructed, but it was observed that error rates gradually decreased with the usage of the interface. Moreover, interviews were given to the therapists to assess aspects such as simplicity, software interaction, configurability, images quality, screen navigation resources and students' evolution: they were evaluated as good. The specialists affirmed that the tool desktop solution, operations and principles, were very easy to understand and use.

\section{AAC mobile solution}

Description: AAC mobile solution is an app based on iconographic symbols. This app is conceived to study the student's cognitive ability: the student selects and groups symbols from different categories according to their relationship (Drag and Drop activity).

User communication needs: supportive language.

Type of communication: communication producing non verbal message (d335), speaking (d330) and conversation (d350).

Communication medium: aided communication using electronic device with speech output.

Input features and selection techniques: scanning or directed scanning using touch.

Messages characteristics (form of AAC and vocabulary expansion): pictures and text.

Output features: pictures and oral description.

Accessory features: not indicated.

Adults' role: not indicated.

The satisfaction using the AAC mobile solution was evaluated using the Usability scale (SUS) Questionnaire. The evaluation process is still ongoing and the first results showed that the software has easy handling application, good images contrast, easy calibration and automatic adjust of the touch screen.

\section{\begin{tabular}{l|l}
\hline ST2 & PPad $^{\mathrm{TM}}$ \\
\hline
\end{tabular}}

Description: the $\mathrm{iPad}^{\mathrm{TM}}$ is provided with a web-based app, 'Tap to Talk', that allows users to design a personal album to make choices of activity and to product customizable phrases. 'Tap to Talk' has both symbol and text-to-speech capabilities. When a child taps on a category voice states in which subject area 
the child is entering. The child then has options to choose from, and the child can tap on the picture.

User communication needs: alternative language.

Type of communication: communication producing non verbal message (d335) and conversation (d350).

Communication medium: aided communication using electronic device with speech output.

Input features and selection techniques: scanning or directed scanning using touch.

Messages characteristics (form of AAC and vocabulary expansion): pictures and text; possibility to implement the vocabulary.

Output features: pictures and oral description.

Accessory features: the app is available for smart phones and tablets, it can be taken anywhere (portable).

Adults' role: the adult has multiple roles in controlling the use of the electronic choice board, in interpreting of the non-speaking participant's turn and also in interpreting and making the choice.

The study highlights how - despite the advantages of portability - the small size of the $\mathrm{iPad}^{\mathrm{TM}}$ screen is problematic for the child who cannot easily access it independently. The iPad ${ }^{\mathrm{TM}}$ has many socially acceptable attributes, but these must be part of the decision: functionality for the child must be the prime. The analysis of the conservation between participants illustrates that interaction with an aid such as the $\mathrm{iPad}^{\mathrm{TM}}$ has to take into account the wide context in which the child lives and all forms of communication being used. The extracts illustrate the challenges and rewards of interacting with a child with a limited repertoire of consistently interpretable responses. In examining the child's communicative opportunities it can be seen that she does not just give yes/no replies. She is persistent in turning her attention to the video camera, not a choice on the $\mathrm{iPad}^{\mathrm{TM}}$ but potentially a freely chosen one.

\section{\begin{tabular}{l|l} 
ST3 & SANYOG
\end{tabular}}

Description: icon-based communication software that accepts a sequence of icons as input and converts the input sequence to a grammatically correct sentence. On the interface of Sanyog, icons representing different linguistic items are displayed. Each of these icons is shown along with its meaning. With the selection of icons from the interface, a user essentially inputs to the system a sequence of root words (corresponding to the sequence of icons).

User communication needs: supportive language. 
Type of communication: communication producing speaking (d330) and conversation (d350).

Communication medium: aided communication using specific software with speech output.

Input features and selection techniques: scanning or directed scanning using variants of pressure switches (three types of hand-operated switches and one type each of mouth and foot-operated switch).

Messages characteristics (form of AAC and vocabulary expansion): pictures and text; possibility to implement the vocabulary.

Output features: pictures and oral description.

Accessory features: not indicated.

Adults' role: not indicated.

Different aspects of the design were evaluated trough a questionnaire. The analysis of the answers highlighted that the special icons were reasonably intuitive and that after using the system for only a week, the subjects became familiar with them. The ease of communication was also considered.

For some users, the QR-based interaction starting from a verb selection and the interface layout was sufficient. However, there were some users for whom the particular model of interaction did not seem very natural, although these users did not have any problem with the interface layout. Positive responses from all of the institutions that user enjoy communicating through Sanyog.

\begin{tabular}{|l|l}
\hline ST4 & FOOD SAFETY, PUBLIC SAFETY AND SUSTAINABLE CITY (DIGITAL GAMES)
\end{tabular}

Description: three digital games, with simple narratives, requiring answers to one problem at a time from the player. The software has a PDA - Personal Digital Assistant - and operates with a free, open-source Linux system.

User communication needs: supportive language.

Type of communication: communication producing speaking (d330) and producing nonverbal messages (d335).

Communication medium: unaided communication, the person communicates by using nonverbal expressions or signs (technology is not a medium of communication but a means of eliciting a person's non-verbal communication methods).

Input features and selection techniques: accessed through a light touch on the icon directly on the touch screen.

Messages characteristics (form of AAC and vocabulary expansion): not indicated.

Output features: not indicated.

Accessory features: not indicated. 
Adults' role: the adult mediator observed the child playing with the digital games and interacted with him through questions, hints, and feedback. The mediator must respect the response time of each individual and be trained from the professional point of view in theoretical and practical fundamental resources of AAC and Assistive Technology in order to work more effectively in the development of communication in nonspeaking children.

Through video registration analysis the progression of communication was evaluated. Two external observers tested the rate of agreement on the evaluation of the videoregistrations performed by the researcher. Then the rate of agreement in each game was calculated. The results of the rate of agreement in each game were satisfactory. Communication increased during the sessions with digital games (gestures, facial expressions, body language, smile, nod, move the eyes), the frequency of occurrence of communication was continuous during the session.

The major gains occurred especially in the initial sessions, even though there was a slight progress in the last ones. The results also suggested the importance of assistive technology for communicative, social inclusion and improved quality of life, enabling persons with Cerebral Palsy access to computer and other devices that promote their interaction with people, and the possibility of using such resources as educational procedures and promoting the development of those children.

\section{\begin{tabular}{l|l} 
ST5 & EYE GAZE TECHNOLOGY
\end{tabular}}

Description: eye gaze technology is an electronic device that allows a person to control a computer by looking at words or commands on a video screen. A very low intensity light shines into one of the user's eyes. A television camera picks up reflections from the cornea and retina. As the direction of the person's gaze moves, the relative position of the two reflections changes, and the computer uses this information to determine the area at which the person is looking. Eye gaze technology allows persons with little or no functional speech and physical disabilities to access electronic AAC systems using movements of their eyes to operate a laptop, computer or speech-generating device.

User communication needs: alternative language.

Type of communication: communication producing nonverbal message (d335).

Communication medium: aided communication using electronic device.

Input features and selection techniques: direct selection. Eye gaze devices activate cells on the computer/tablet screen.

Messages characteristics (form of AAC and vocabulary expansion): singlemeaning graphic symbols (Widgit or PCS). 
Output features: speech generating device.

Accessory features: not indicated.

Adults' role: partners need to appropriately scaffold communicative exchanges and to take responsibility for ensuring optimal functioning to the system, adapting the task and materials as well as setting up the environment in a way that ensures access. Partners' willingness, ability and confidence to set up and adjust the eye gaze and AAC technology play an important role.

The study found that the purchase and maintenance of the device are particularly expensive. Regarding the communication process, one of the mothers involved in the research expressed concerns about the possibilities of the technology to improve the difficult communication challenges. A family, moreover, has declared not to use in all the contexts of life the device thus reducing the number of possible interactions of their son. Other stakeholders highlighted how some aspects of the technology itself (e.g. synthesized speech) were not accurate.

\begin{tabular}{|l|l} 
ST6 & VOCA \\
\hline
\end{tabular}

Description: Voice Output Communication Aids (VOCA) are electronic devices that are able to generate printed and/or spoken text. Many different products are available: some of them are dedicated for communication purposes while others are software programs in lap-top computer systems. Additional features (such as appointment schedules and reminders, simple environmental control units, alternative access methods, dual displays, and abbreviation expansion programs) can be provided.

User communication needs: supportive language.

Type of communication: conversation (d350).

Communication medium: aided communication using electronic software with speech output.

Input features and selection techniques: not indicated.

Messages characteristics (form of AAC and vocabulary expansion): pictures.

Output features: printed and spoken text.

Accessory features: not indicated.

Adults' role: the family and sibling support are important component of digital technologies used and high levels of collaboration may be needed. Young people who use AAC are at a risk of digital exclusion if these levels of support are not in place.

The evaluation of the increase of the perceived self-determination using the internet was assessed. Six analytical categories (desire to be online, selfdetermination, self-representation, enriched friendships, access technology, 
describing support) were analyzed using interviews. Difficult controls prevented participants from using entertainment activities, which are known to be popular among young people The other main barrier to independent access was literacy The limitations for self-representation within face-to-face conversations appear to be alleviated by the use of Online Social Media (OSM) sites.

A Facebook identity offered the participants an opportunity to show their humor, create personal narratives and use the timeline to create an historical framework, all of which can be limited on traditional AAC technology. The participants demonstrated a strong interest in using OSM to keep in touch over distance.

\begin{tabular}{l|l} 
ST7 & SPEECH RECOGNITION SOFTWARE (SRS)
\end{tabular}

Description: Speech Recognition Software (SRS) is a software that allows the user to operate a computer by speaking into a microphone, rather than using a keyboard and mouse It is a type of Assistive Technology (AT) to compensate for physical writing incapacities and facilitate written expression. SRS offers individuals an opportunity to overcome the barriers that inhibit their independent completion of legible written work and increases their participation by reducing their reliance on assistants to scribe for them. SRS is prescribed for those whose ability to write in an independent and efficient manner is compromised. The original versions of SRS used discrete speech recognition where the user must separate all words or commands with a pause. The current software programs use continuous speech recognition where the user can speak in their normal cadence, using sentences or phrases.

User communication needs: expressive language.

Type of communication: producing written messages (d345).

Communication medium: aided communication using speech recognition electronic software.

Input features and selection techniques: headset microphone.

Messages characteristics (form of AAC and vocabulary expansion): not indicated.

Output features: written text.

Accessory features: not indicated.

Adults' role: not indicated.

The reasons that led users to abandon the use of the software were evaluated through interviews. Among the elements that emerged, the major obstacles highlighted in using the SRS included: poor word recognition, low satisfaction with overall accuracy of the dictated work, noise interference at home and at school, and decreased efficiency in producing a written document. 


\section{Discussion}

This systematic review investigated the researches focused on technologies for the AAC in the decade 2007-2017. Seven articles were identified according to the inclusion criteria. Several elements related to both the technologies used in the AAC and their effects in increasing the communicative potential of persons with motor disabilities were considered.

The analysis of the different papers revealed that research in the AAC technologies sector is still an ongoing process as regards both the technological aspects (hardware and software components) and the evaluation of the effects deriving from their use in the communication process. In relation to the technological aspects, the evaluation tools used in the investigated studies focused on two elements considered crucial: frequency and accuracy of the enunciation. These evaluation parameters represent those normally used in the evaluation processes of AAC technologies (Baxter et al., 2012).

Regarding the second aspect, the studies investigated highlight the growing importance of a systemic evaluation process that sees in the person with disability, in his needs and in the analysis of his life contexts the founding nucleus. Investigations in this area increasingly seem to be aimed at capturing the users' needs, their ways to relate with the others and their wish to have useful and effective technologies, less stigmatizing and able to open up to virtual reality.

Some technologies among those concerned in these studies, such as Voice Output Communication Aid (VOCA) and Speech Recognition Software (SRS), have always belonged to the AAC field (Campbell et al., 2002; McNaugthon et Bryen, 2007). However the software are constantly evolving with the purpose of improving the functionality and the quality of the output features. An example in this direction is represented by the language generation software, that includes icon prediction methods to speed up the scanning process, thanks to query-based programming (Bhattacharya \& Basu, 2009).

Currently mobile devices seem to have the highest potential for future developments in the AAC fields: their features include greater portability compared to the traditional hardware (PC); additional advantages are related to the possibility of installing different APPs, also available for free, to support communication in different life contexts (Pinto et Gardner, 2014). In this way the mobile devices could represent useful tools to make the access to AAC technologies more democratic (Dolic et al., 2012; Light et McNaugthon, 2013); their widespread use by persons with typical development greatly reduces the stigmatizing component traditionally associated with other AAC technologies.

It is also important to note that the opportunity to install and use different APPs represents a real revolution in the field of AAC as it generates, already 
in the short term, a growing direct connection between software developers and end consumers, determining the disappearance of the intermediate phase represented by the research, experimentation and evaluation of the developed software (Beukelman, 2012).

However, it is necessary to underline, as in the case of severe motor disability, these devices and the touch screen access represent a real obstacle (Pinto et Gardner, 2014) requiring sophisticated skills of motor coordination (Saturno et al., 2015).

A possible solution to this problem may be represented by whether the gaze technology (Niekerk et Tönsing, 2014) or the Brain Computer Interface (BCI) which uses electrophysiological signals (Birbaumer 2006). In both cases using a non-muscular channel would increase the potential of communicative output of individuals with severe motor disabilities and with absent or limited possibilities of verbal and non-verbal language (Tai et al, 2008).

The examined studies also highlighted that to deploy the potential offered by the technologies a continuous use and an adequate training are needed. It becomes therefore necessary to plan appropriate training sessions, not only addressed to the users, but also to family members, caregivers and peers (Saturn et al., 2015; Niekerk et Tönsing., 2014; Schyndel et al., 2014).

Partners in fact play a fundamental role in promoting an effective use of technologies, and throughout the communication process, because they may become effective communication scaffolders (Saturno et al., 2015; Hynan et al., 2014). This support should be aimed at developing the technological skills in order to allow users to enhance a communicative process characterized by the reduction of the scanning times with acceptable conversation turns in terms of time duration and by the production of syntactically correct messages (Ferm et al. 2005; Clarke et Wilkinson, 2010)

Training duration times are closely related to the type of disability (with reference to motor limitations and cognitive functioning) and to the complexity of the technology (Waller et al., 2005). Some studies (Niekerk et Tönsing, 2014; Schyndel et al., 2014) significantly underline that the design and subsequent implementation of technologies for AAC should be oriented towards the principles of user centered design (Andrews et al., 2012). Designing technologies according to this perspective implies that it would be possible to implement solutions more clearly addressed to take into account the users' characteristics, their needs and potentialities; this means to adopt a recursive production model of prototype realization and evaluation, that involves users themselves, before reaching the final product development (Lubas et al., 2014). In this way it would also be possible to limit the risks deriving from the development of technological solutions perceived as not functional or stigmatizing by the users, that for these reasons are rapidly abandoned, causing 
a progressive social exclusion of this part of the population (Ball et al., 2007; Schyndel et al., 2014).

Moreover, an ecological approach should be added to the perspective of user-centered design: according to Schyndel et al. (2014) this means considering not only the specific needs of the persons with disabilities but also their relationships with the meso- and the macrosystem (Bronfenbrenner $\&$ Morris, 2006) trying to improve the match between the possible technological solutions with their needed features and with the production costs. In fact, accessibility to such technologies is still limited for the economically most depressed or underdeveloped areas, with negative consequences on the process of real social inclusion of the persons involved (Niekerk et Tönsing, 2014).

Access to social media by persons with complex communication needs, although reported in a single study (Hynan et al., 2014) highlights the need for research to study this field in-depth: on the one hand the number of possible communication partners is virtually extended but on the other hand the possibilities of using non-verbal forms of communication are reduced.

Non-verbal communication is a fundamental form of communication for persons with severe motor disabilities that must be incentivized and extended in both quantitative and qualitative terms. The technologies also in this case can represent a valid support. An example in this case comes from the use of digital games to implement non-verbal communication methods by subjects with severe motor disability. This area of research also requires further study and targeted insights (Ferreira et al., 2013).

\section{Conclusion}

The present study, aimed at identifying the most recent technologies used in the field of AAC, has allowed highlighting some of the current research lines that are characterizing the wide sector of the AAC. These research areas emerged refer specifically to the development of:

- software for reducing response times;

- software for the syntactic correctness of linguistic productions;

- technological solutions for access to social media;

- technological solutions for access to electronic devices.

This systematic review has different limitations. The study investigated the technology solutions developed and tested in this area in the last ten years, although most studies refer to the last 5 years, but the reflection on specific elements related to technologies, their complexity and their degree of innovation, remains complex. 
This complexity is due to some shortcomings in the high tech terminology field (Baxter et al., 2012). Low-technology (low-tech systems) usually includes non-electronic communication devices, while high tech included all the tools that rely on any electronic component (Cook \& Polgar, 2012). However, if in this way the boundary between the low and the high technologies is clarified, it is still difficult to make classifications within the high tech category, that is characterized by a rapid progression. Components, devices and electronic systems considered only a few years ago as high technologies could now represent tools that are now outdated and considered obsolete and old.

All the studies included in this review report the effects of the interventions carried out by using AAC technology, but there is a lack of high quality evidence of the outcomes, due to the limited number of studies based on high quality research designs. Indeed, the studies are based on qualitative designs in which control groups are not adopted, and in which the modalities adopted for recruiting the sample are not always explicated.

Currently there is a lack of experimental studies, which must represent a future priority in order to broaden the knowledge in this field. Only studies of this type could be able to firmly establish the effects of technologies in supporting the social inclusion of people with disabilities.

\section{References}

Andrews, C., Burleson, D., Dunks, K., Elmore, K., Lambert, C., Oppegaard, B., Zobel, G. (2012). A new method in user centered design: Collaborative prototype design process. Journal of Technical Writing \& Communication, 42: 123-142. DOI: 10.2190/TW.42.2.c.

Beukelman, D. (2012). AAC for the 21st century: Framing the future. Presentation at the State of the Science Conference for the RERC on Communication Enhancement, Baltimore, MD.

Birbaumer, N. (2006). Breaking the silence: brain-computer interfaces (BCI) for communication and motor control. Psychophysiology, 43(6): 517-532. DOI: 10.1111/j.1469-8986.2006.00456.x.

Beukelman, D.R., \& Mirenda, P. (2005). Augmentative and Alternative Communication: Management of Severe Communication Disorders in Children and Adults ( $3^{\text {rd }}$ ed.). Baltimore, MD, USA: Paul H. Brookes Publishing Co.

Bhattacharya, S., \& Basu, A. (2009). Design of an iconic communication aid for individuals in India with speech and motion impairments. Assistive Technology, 21(4): 173-187. DOI: 10.1080/10400430903246035.

Blackstone, S.W., Williams, M.B., \& Wilklins, D.P. (2007). Key principles underlying research and practice in AAC. Augmentative and Alternative Communication, 23(3), 191-203. DOI: 10.1080/07434610701553684. 
Bronfenbrenner U., Morris L. (2006). The bioecological model of human development. In Lerner R.M., Damon W. (Eds). Handbook of Child Psychology, $6^{\text {th }}$ ed. Hoboken, NJ: John Wiley \& Sons.

Campbell, L., Balandin, S., \& Togher, L. (2002). Augmentative and alternative communication use by people with traumatic brain injury: a review. Advances in Speech Language Pathology, 4(2): 89-94. DOI: 10.1080/14417040210001669311.

Clarke M., \& Wilkinson R. (2010) Communication aid use in children's conversation: Time, timing and speaker transfer. In Gardner H, and Forrester M (eds.). Analysing interactions in childhood: Insights from conversation analysis. Wiley: Blackwell.

Cochrane Library (2011). Cochrane Handbook for Systematic Reviews of Interventions. Testo disponibile al sito: http://training.cochrane.org/handbook (4/03/2018).

Cook, A.M., \& Polgar, J.M. (2012). Assistive Technologies-E-Book: Principles and Practice. Elsevier Health Sciences.

Ferm U., Ahlsen E. and Bjorck-Akesson E. (2005). Conversational topics between a child with complex communication needs and her caregiver at mealtime. Augmentative and Alternative Communication, 21: 19-40. DOI: 10.1080/07434610412331270507.

Ferreira, M.I.J., Travassos, X.L., Sampaio, R., \& Pereira-Guizzo, C.D.S. (2013). Digital Games and Assistive Technology: Improvement of Communication of Children with Cerebral Palsy. International Journal of Special Education, 28(2): 36-46.

Gross, J. (2010). Augmentative and alternative communication: a report on provision for children and young people in England. Retrieved January, 19.

Hynan, A., Murray, J., \& Goldbart, J. (2014). 'Happy and excited': Perceptions of using digital technology and social media by young people who use augmentative and alternative communication. Child language teaching and therapy, 30(2): 175-186. DOI: $10.1177 / 0265659013519258$.

Kitchenham, B. (2004). Procedures for performing systematic reviews. Keele, UK, Keele University, 33: 1-26.

Law, M., Stewart, D., Letts, L., Pollock, N., Bosch, J., \& Westmorland, M. (1998). Guidelines for critical review of qualitative studies. McMaster University Occupational Therapy Evidence-Based Practice Research Group.

Light, J., McNaughton, D. (2012). Supporting the communication, language, and literacy development of children with complex communication needs: State of the science and future research priorities. Assistive Technology, 24(1): 34-44. DOI: 10.1080/07434610701553635.

Lindsay, G., Dockrell, J., Desforges, M., Law, J., \& Peacey, N. (2010). Meeting the needs of children and young people with speech, language and communication difficulties. International Journal of Language \& Communication Disorders, 45(4), 448-460. DOI: 10.3109/13682820903165693.

Lubas, M., Mitchell, J., \& De Leo, G. (2014). User-centered design and augmentative and alternative communication apps for children with autism spectrum disorders. Sage Open, 4(2): 1-10. DOI: 10.1177/2158244014537501.

Mcnaughton, D., \& Bryen, D.N. (2007). AAC technologies to enhance participation and access to meaningful societal roles for adolescents and adults with developmental disabilities who require AAC. Augmentative and Alternative Communication, 23(3): 217-229. DOI: 10.1080/07434610701573856. 
Millar, S., \& Scott, J. (1998). What is Augmentative and Alternative Communication? An Introduction. In A. Wilson (Ed.), Augmentative Communication in Practice: An Introduction (pp. 3-12). Edinburgh: University of Edinburgh CALL Centre.

Moed, H.F. (2010). Measuring contextual citation impact of scientific journals. Journal of informetrics, 4(3): 265-277. DOI: 10.1016/j.joi.2010.01.002.

Owlia, P., Vasei, M., Goliaei, B., \& Nassiri, I. (2011). Normalized impact factor (NIF): an adjusted method for calculating the citation rate of biomedical journals. Journal of biomedical informatics, 44(2): 216-220. DOI: 10.1016/j.jbi.2010.11.002.

Pinto, M., Gardner, H. (2014). Communicative interaction between a non-speaking child with cerebral palsy and her mother using an iPadTM. Child language teaching and therapy, 30(2): 207-220. DOI: 10.1177/0265659013518338.

Royal College of Speech and Language Therapists. (2006). Communicating Quality3: RCSLT's guidance on best practice in service organisation and provision. Testo disponibile al sito: RCSLT: www.rcslt.org/speech_and_language_therapy/standards/ CQ3_pdf (4/03/2018).

Saturno, C.E., Ramirez, A.R.G., Conte, M.J., Farhat, M., Piucco, E.C. (2015). An augmentative and alternative communication tool for children and adolescents with cerebral palsy. Behaviour \& Information Technology, 34(6): 632-645. DOI: 10.1080/0144929X.2015.1019567.

UN General Assembly (2006). Convention on the Rights of Persons with Disabilities. United Nations. www.un.org/development/desa/ disabilities/convention-on-therights-of-per- sons-with-disabilities.html (5/03/2018).

Van Niekerk, K., \& Tönsing, K. (2015). Eye gaze technology: A South African perspective. Disability and Rehabilitation: Assistive Technology, 10(4): 340-346. DOI: 10.3109/17483107.2014.974222.

Van Schyndel, R., Furgoch, A. B., Previl, T., \& Martini, R. (2014). The experience of speech recognition software abandonment by adolescents with physical disabilities. Disability and Rehabilitation: Assistive Technology, 9(6): 513-520. DOI: $10.3109 / 17483107.2014 .883651$.

Von Tetzchner, S., \& Martinsen, H. (1992). Introduction to Sign Teaching and the Use of Communication Aids. London, United Kingdom: Whurr Publishers.

Waller, A., Balandin, S.A., O'mara, D.A., Judson, A.D. (2005). Training AAC users in user-centred design. Proceedings of the Accessible Design in the Digital World 2005 Conference: 1-7. www.bcs.org/upload/pdf/ewic_ad05_s1paper2.pdf $(4 / 03 / 2018)$.

World Health Organization (2001). International Classification of Functioning, Disability, and Health. Geneva $(\mathrm{CH})$ : World Health Organization. 